\title{
Early Childhood Education Psychoeducation during the COVID-19
}

\author{
Rikha Surtika Dewi*, Maesaroh Lubis, Elfan Fanhas Fatwa Khomaeny, Fajar \\ Nugraha, Lusiana Tapiah
}

\author{
Department of Early Childhood Education, Faculty of Education and Teacher Training \\ Muhammadiyah University of Tasikmalaya, Jl. Tamansari Km. 2,5 Kota Tasikmalaya \\ *Corresponding Author: rikha.surtika@umtas.ac.id
}

\begin{abstract}
A b s trak
The COVID 19 pandemic has made various changes in people's lives, also on Early Childhood Education. The Children hve been affected both directly and indirectly in formal and non-formal education, both education by parents and related institutions. Early Childhood Education and components of the system of education encountered various obstacles related to the implementation of children's activities during social restrictions. Referring to this problem, this Community Partnership Program activity is intended as an effort to anticipate obstacles that occur in Early Childhood Education during the pandemic situation. This Community Partnership Program is implemented through the Psychoeducation Activity Program which focuses on Early Childhood Education. The Psychoeducation Program use an intervention method that can be applied to individuals, families, and groups that focus on educating participants about significant challenges in life, helping participants develop sources of support and social support in facing, and developing coping skills to face these challenges.
\end{abstract}

\begin{tabular}{l}
\hline \multicolumn{1}{c}{ A r t i c I e I n f o } \\
\hline Article History: \\
Received 1 November 2021 \\
Revised 10 November 2021 \\
Accepted 20 November 2021 \\
Available online 15 January 2022 \\
Keywords: \\
Covid 19 Pandemic, \\
Early Childhood Education, \\
Psychoeducation
\end{tabular}

\section{INTRODUCTION}

The Introduction contains the urgency and background of community service issues described by the inverted pyramid method starting from the global, national and local levels. Include references (literature or result of research references) by using the source number in each sentence after the sign (.) which is adjusted to the bibliography, for example: Strasburger The COVID 19 pandemic situation has changed the structure of people's lives, so for the all learning process activities, formal and non-formal education, from early childhood education to higher education, has been affected by this pandemic situation. Learning activities carried out now is online learning. This is a problem for the teachers, parents and society on how to create economic stability, social and psychological perspective.

Various problems appear in all aspects of community life, including in the field of early childhood education. Children had affected direct or indirect impact of the various situations, many parents with their problems which are related by income, employment, emotional stability and many other problems which affect to the situation in the family and one of them affects the children. In the formal education, people are currently faced with a situation of online learning activities, where educational activities are carried out from home. 
Although the essence of early childhood education is family, in fact the current of situation presents other phenomena. Many parents complain of difficulties in providing optimal without formal education assistance. The children feel bored with activities at home and are considered stressors compared to school, have difficulty meeting friends and miss the figure of a teacher. On the other hand, the teacher tries hard to create creativity and effective learning methods during home learning for children.

The various problems that have been described above require proper handling and as soon as possible considering the pandemic situation which can be predicted when it will end, and it is indicated that the end of this pandemic we are faced with new normalities and it is difficult to return to normal as before where the pattern of people's lives changes, health protocols are increasingly active and learning and educational activities that must be adapted to the online system.

One of the very important efforts to make related to how early childhood children can continue to receive optimal education, care and assistance is to ensure that good faith is established between parents, educational institutions / schools, teachers, and the general public regarding the nature of Early Childhood Education, competency and skills development as well as creativity and innovation in various activities organized in early childhood education during this pandemic and in the future.

\section{MATERIALS AND METHODS}

The method used in this Community Partnership Program is a psychoeducation program. Psychoeducation is an intervention that can be carried out on individuals, families, and groups that focus on educating participants about significant challenges in life, helping participants develop sources of support and social support in facing these challenges, and developing coping skills to face these challenges. (Griffith, 2006 quoted from Walsh, 2010). Psychoeducation is a treatment that is given in a professional manner which integrates psychotherapeutic interventions and education (Lukens \& McFarlane, 2004)

Psychoeducation can be applied not only to individuals or groups who have psychiatric disorders, but is also used so that individuals can face certain challenges at each level of human development so that they can avoid problems related to the challenges (Walsh, 2010). Psychoeducation is a process empowerment to develop and strengthen existing skills to suppress the emergence of a mental disorder (Walsh, 2010). Because psychoeducation can be applied as part of one's preparation to face various challenges in every stage of life development, psychoeducation can be applied in almost every setting of life. In addition, because of its flexible model, which combines information related to certain disorders and tools to deal with certain situations, psychoeducation has the potential to be applied to external areas related to various forms of disorders and various life challenges (Lukens \& McFarlane, 2004).

\section{RESULTS}

This psychoeducation activity was carried out online through a zoom meeting room and live youtube of the PG PAUD FKIP UMTAS study program by involving elements of teachers, parents, students, lecturers and several institutions and partners with national level speakers, both practitioners and academics. Various partner problems related to the implementation of education with the concept of learning from home (BDR), should be familiar to the realm of early childhood education because the essence of early childhood education is to start at home. But in fact there are various problems that arise during learning from home activities on the COVID-19 pandemic situation. These are about the participants' understanding of the pandemic situation, distance learning for early childhood, readiness and participation of parents and 
families, problems of creativity, building cooperation between parents and educational institutions / teachers, psychological problems of children and parents.

The number of participants in this activity was 307 participants with various backgrounds from students, teachers, parents, representatives of institutions / organizations and the general public. Based on the results of the evaluation of the activities, in general the participants gave very useful responses to this psychoeducation activity, the suitability of the material and competence of the resource persons were also considered very appropriate and satisfying and the formation of new understanding and skills for participants in optimizing early childhood education during the pandemic from various perspectives.

\section{DISCUSSION}

The implementation of community partnership program activities through psychoeducation activities for teachers and parents and students is carried out as a form of concern and efforts to optimize early childhood education services in the situation of the COVID-19 pandemic situation. Based on field findings obtained through observations and interviews with partners, conclusions are obtained about the urgency of need understanding and knowledge and special skills both in terms of pedagogy and stimulation of creativity in elements related to early childhood education services in order to support the achievement of optimization of development expected for early childhood through various activities and meaningful activities. Referring to these findings, a partnership between the PG PAUD academic community of Muhammadiyah University of Tasikmalaya was carried out with HIMPAUDI and IGTKI Tasikmalaya to organize a workshop and mentoring for teachers, parents and students which aims to increase knowledge, understanding and skills in accompanying early childhood especially during activities on Covid 19 pandemic which relied more on activities in their homes. The goals of psychoeducation put forward by Brown (2011) that psychoeducation, both individuals and groups, not only provides important information related to the problems of its participants but also teaches skills that are considered important for participants to deal with problem situations.

Based on the results of its implementation, it can be concluded that mentoring activities through workshops, seminars and trainings is needed and produces a positive impression for all parties. Various partner problems related to the implementation of education with the concept of learning from home (BDR), should be familiar to the realm of early childhood education because the essence of early childhood education is to start at home. But in fact there are various problems that arise during BDR activities during the Covid 19 pandemic, starting from the readiness of parents, limited creativity of teachers, the bored felt by children and parents in social distancing and many more. Rohayani (2020) in his research entitled answering problems faced by early childhood during the Covid 19 pandemic, which resulted in the conclusion that during the Covid-19 pandemic, there were several problems that appeared, such as parents who treat gadgets as a child's friend when the child feels bored, the lack of parent intervention in the child's world, the problems of parents in dealing with children and also the saturation of parents and children during this pandemic. Another research conducted by Tabi'in (2020) on the problem of at home stay in early childhood in the midst of the Covid 19 pandemic, which result in findings on various problems that arise in early childhood, these problems is stress, increased sensitivity, temper-tantrums, spoiled and behavioral disorders. This research is in line with the findings experienced by partners as institutions that protect various early childhood education services aged 4-7 years.

So can be concluded that the implementation of psychoeducation is in accordance with the needs of partners and the elements involved in it, especially in the implementation of early 
childhood education services during the Covid 19 pandemic.. Referring to the results of this activity, it is hoped that similar activities can be carried out more continuously and intensively to maintain quality and optimize the achievement of early childhood development stages according to their spirit. As well as the cooperation of all parties, in this case of parents, teachers, institutions and society have a very important role in the implementation of comprehensive early childhood education services during this pandemic, without cooperation, the obstacles that arise will be difficult to overcome so that it will have an impact on service quality. education for early childhood.

\section{CONCLUSIONS AND SUGGESTIONS}

Based on the results of the psychoeducation activities, several conclusions have been found regarding the urgency of the importance of cooperation of all parties in building quality early childhood education on the Covid 19 pandemic situation for the teachers, parents and academics, practitioners and society need to work together to create early childhood education that remains optimal according to the task of early childhood development amid the current pandemic situation. This community partnership program carried out a form of psychoeducation in supporting early childhood education services in the Covid 19 pandemic situation.

Several things that were suggested related to optimize early childhood education during a pandemic situation ; 1 ) increasing cooperation and effective communication between parents and teachers / institutions, 2) increasing institutional cooperation with other educational institutions or early childhood education organizations in providing understanding and improving the skills and creativity of teachers to adapt the distance learning, 3) The next step is to improve digital literacy for teachers and parents as a support in obtaining information on learning resources or other information, 4) increasing "learning sharing sessions" as an effort to minimize learning and parenting problems during the pandemic to reduce negative impacts about distance learning activity.

\section{ACKNOWLEDGMENTS}

Special Thanks to the leadership of the University of Muhammadiyah Tasikmalaya who have support to the author in conducting the research. Thank you for the support of all colleagues; The Institute for Research and Community Service, The Academic Community of Department of Early Childhood Education, PIAUD Study Program of UIN Syekh Gunung Jati Cirebon, Indonesian Kindergarten Teacher Association (IGTKI) Tasikmalaya, Indonesian Early Childhood Education Association (Himpaudi), Tasikmalaya, Teacher Association of Aisyiyah Bustanul Athfal (IGABA) Tasikmalaya, Teacher Association of Raudhatul Athfal (IGRA) Tasikmalaya, Edu Publisher Tasikmalaya, PAUD IT Ihya As-Sunnah Tasikmalaya, MDMC Pangandaran Regency.

\section{REFERENCES}

Brown, Nina W. (2011). Psychoeducational Groups $3^{\text {rd }}$ Edition: Process and Practice. New York: Routledge Taylor \& Francis Group

Luken, EP, \& McFarlane, WR (2004) Psychoeducation as Evidence-Based Practice: Considerations for Practice, Research, and Policy. Brief Treatment and Crisis Intervention Vol. 4 No. 3, a Oxford University Press 2004; all rights reserved

Rohayani, F. (2020). Answering the Problems Faced by Early Childhood During the Covid Pandemic 19. QAWWAM, 14(1), 29-50. https://doi.org/10.20414/qawwam.v14i1.2310

Tabi'in, A. (2020)Problems in Stay At Home Early Childhood Amid the Covid Pandemic 19. Journal of Golden Age, Hamzanwadi University Vol. 04 No. 1, June 2020, P. 190-200. 
Walsh, Joseph. (2010) Psycheducation in Mental Health. Chicago: Lyceum Books, Inc. 


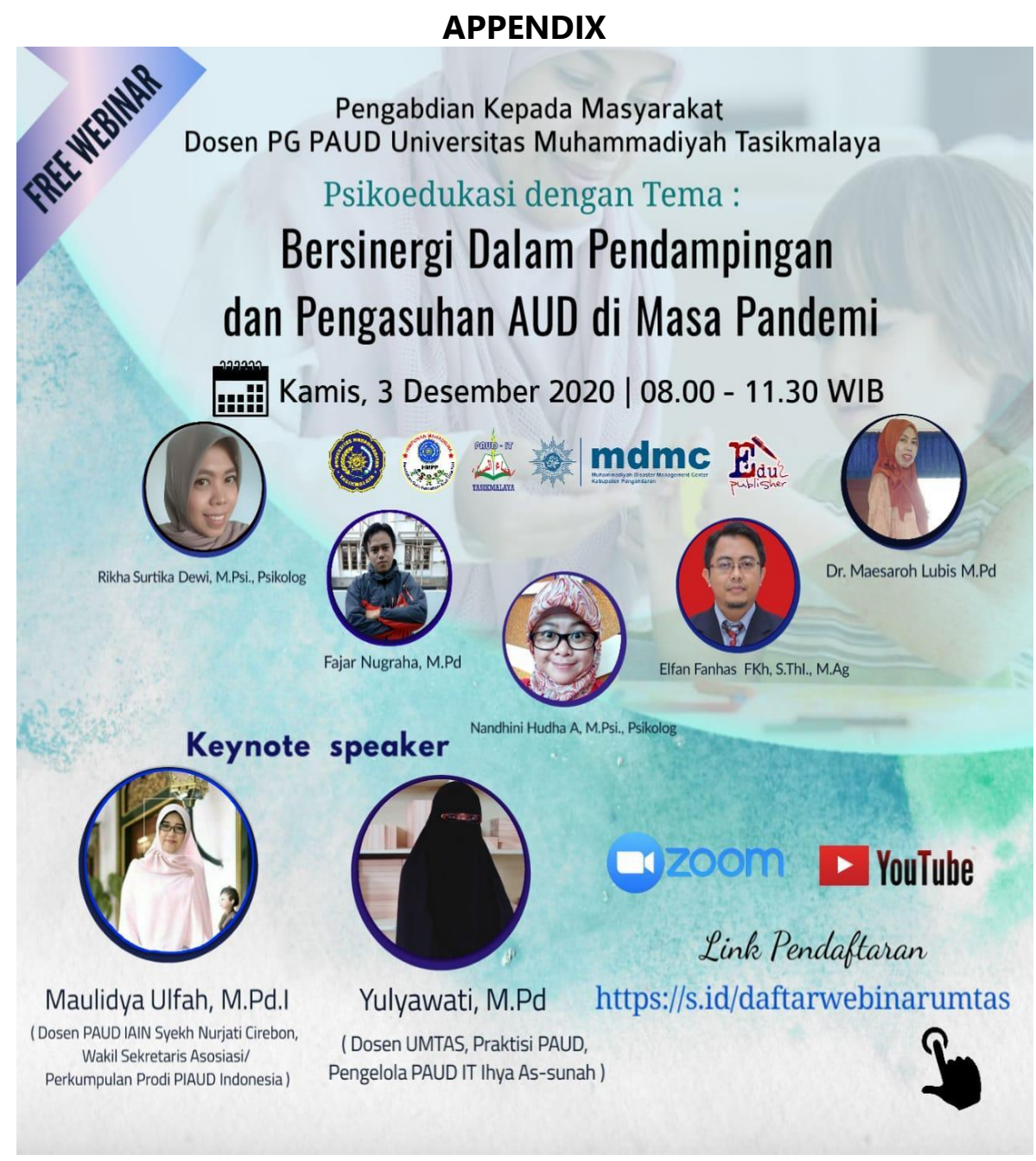

Figure 1. Flyer Webinar

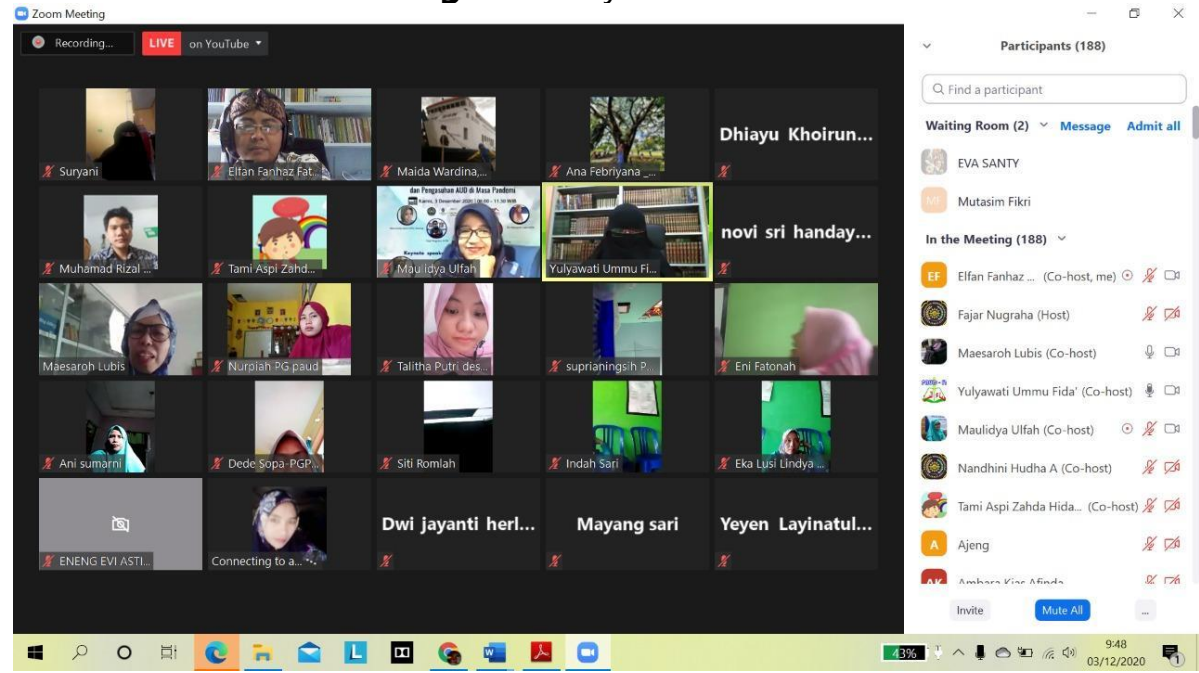

Figure 2. Zoom Webinar Participants 


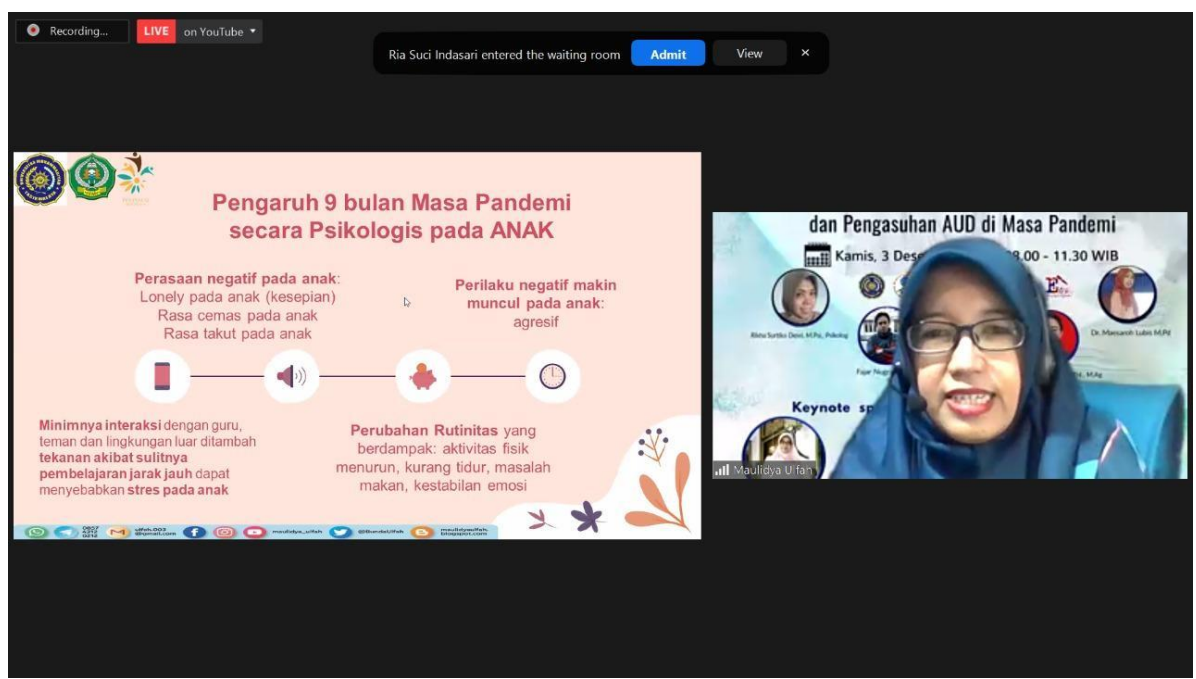

Figure 3. Presentation of Material from Resource Person 